Preface

\title{
Maintaining Hemostasis and Preventing Thrombosis in Coronavirus Disease 2019 (COVID-19): Part II
}

\author{
Emmanuel J. Favaloro, PhD, FFSc (RCPA) ${ }^{10}$ Giuseppe Lippi, MD²0 \\ ${ }^{1}$ Department of Haematology, Institute of Clinical Pathology and \\ Medical Research (ICPMR), Sydney Centres for Thrombosis and \\ Haemostasis, Westmead Hospital, Westmead, Australia \\ 2 Section of Clinical Biochemistry, University of Verona, Verona, Italy \\ Semin Thromb Hemost 2021;47:333-337.
}

Welcome to another issue of Seminars in Thrombosis and Hemostasis (STH). This issue is published under the "banner" of "Maintaining hemostasis and preventing thrombosis in coronavirus disease 2019 (COVID-19) : Part II"; this being the second such issue. The first issue was published in 2020 and has proved very popular with the STH readership., COVID-19 is caused by severe acute respiratory syndrome coronavirus 2 (SARS-CoV-2). Believed to originate from Wuhan City in China, with the first reported case in December 2019, at time of writing, there were over 113 million cases reported worldwide, and over 2.5 million attributable deaths. ${ }^{3}$ This compares to 26 million cases reported worldwide, and nearly 900,000 attributable deaths, at the time of writing the first COVID-19 issue Preface (August 30, 2020). ${ }^{1}$ From a smattering of reports in the scientific literature in late $2019(n=228)$, there are now over 100,000 publications ascribed to COVID-19 in PubMed, including almost 12,000 reviews. This compares to 51,000 publications, including over 5,000 reviews, at the time of writing the first COVID19 issue Preface. ${ }^{1}$ Thus, cases of COVID-19 have continued to grow at a fast pace, deaths attributable to it have tripled, and publications doubled since the first issue Preface, a short half year ago. ${ }^{1}$ As this intriguing virus continues to mutate, evolves, and attempts to adapt to the host (i.e., us), this may continue to be the state of play, at least for the immediate future.

Given this continued and vast explosion of information, it is impossible to keep up with the literature on COVID-19. Also, given this plethora of information, one wonders what novel information we could add to the pile? In the first STH issue on COVID-19, ${ }^{1}$ the editorial team of STH contributed enormously by generating a series of commentaries, which have proved very popular. ${ }^{2}$ One situation that was clear to us at that time was that given the great interest and initial thirst for knowledge, all journals became very interested in pub- lishing on COVID-19 and, indeed, many papers were fast tracked to publication, and some have since been retracted. The STH board decided that although STH needed to publish on COVID-19, it did not want to publish just anything on COVID-19, and so a fairly resistant stance to acceptance of COVID-19 papers, just because they mentioned COVID-19, was undertaken. STH did not want to publish misinformation, or additional "me too" papers (e.g., reviews similar to those that had already been published elsewhere). We continue to resist publishing on COVID-19 just for the sake of publishing on COVID-19. Hence, it has taken some 6 months to accumulate enough material to collate into this second issue on COVID-19. This is not to imply that this issue contains dated papers. The Publisher has agreed to fast track accepted COVID-19 papers, and these all appear on eFirst ahead of print publication. Indeed, one of the papers in the current collation appeared on eFirst just after finalizing the first issue (on September 3, 2020). ${ }^{1}$

As mentioned, a bulk of prior COVID-19 papers previously published by STH were commentaries. ${ }^{1}$ Accordingly, it seems fitting to start this second issue with the residual of the commentaries that we initially planned to publish. ${ }^{4-6}$ First, Harenberg and colleagues ask the pertinent question of does chronic treatment with oral anticoagulants ameliorate the clinical course of SARS-CoV-2 infection in COVID-19? The second Commentary in this issue is by Amgalan and colleagues, who discuss sex- and gender-specific differences to help explain why men appear to be at greater risk of developing severe COVID-19. ${ }^{5}$ Although the content may appear a little tangential to the STH scope, being thrombosis and hemostasis, we need to remember that COVID-19 is largely a vascular disease, and that severe COVID-19 manifests with thrombosis in around one-third of affected patients, and even more in those needing mechanical ventilation and/or intensive care. ${ }^{7}$ Notably, all the three essential elements that
Address for correspondence Emmanuel J. Favaloro, PhD FFSc (RCPA), Department of Haematology, Institute of Clinical Pathology and Medical Research (ICPMR), Westmead Hospital, Westmead, Australia (e-mail: emmanuel. favaloro@health.nsw.gov.au).
Issue Theme Maintaining Hemostasis and Preventing Thrombosis in COVID-19-Part II; Guest Editors: Emmanuel ]. Favaloro, PhD, FFSc (RCPA) and Giuseppe Lippi, MD. (c) 2021. Thieme. All rights reserved. Thieme Medical Publishers, Inc., 333 Seventh Avenue, 18th Floor, New York, NY 10001, USA
DOI https://doi.org/ 10.1055/s-0041-1728775. ISSN 0094-6176. 
compose the Virchow's triad can be found in COVID-19, as shown in -Fig. 1. The final commentary in this issue is by Nadir and Brenner, on the relevance of heparan sulfate and heparanase to severity of COVID-19 in the elderly. ${ }^{6}$ Again, we make additional reference here to the fact that the elders are those most at risk of death and morbidity from COVID-19. Of interest, STH has recently also finalized a separate issue on heparan sulfate, heparanase, and other proteoglycans, and their roles in hemostasis and beyond. ${ }^{8}$

Given the relevance of thrombotic risk in COVID-19, many of the subsequent contributions accordingly relate to this. First are two original studies related to COVID-19. ${ }^{9,10}$ Initially, Fernández-Capitán and coworkers discuss the presenting characteristics, treatment patterns, and outcomes among patients with venous thromboembolism (VTE) during hospitalization for COVID-19. ${ }^{9}$ Although VTE is common in patients with COVID-19, limited data exist on patient characteristics, treatments, and outcomes. This manuscript describes a prospective multinational study of patients with incident VTE during the course of hospitalization for COVID-19. Data were obtained from the Registro Informatizado de la Enfermedad TromboEmbólica (RIETE) registry. Allcause mortality, VTE recurrences, and major bleeding during the first 10 days were separately investigated for patients in hospital wards versus those in intensive care units (ICUs). At the time of study end, a total of 455 patients were diagnosed with VTE (83\% pulmonary embolism [PE], 17\% isolated deep vein thrombosis [DVT]) during their hospital stay; $71 \%$ were male and the median age was 65 (interquartile range: 55-74) years. Most patients (68\%) were hospitalized in medical wards, and 145 in ICUs. Three hundred and seventeen (88\%; 95\% confidence interval [CI]: 84-91\%) patients were receiving thromboprophylaxis at the time of VTE diagnosis. Most patients (88\%) received therapeutic low-molecularweight heparin, and 15 (3.6\%) received reperfusion therapies. Among 420 patients with complete 10-day follow-up, 51 (12\%; 95\% CI: 9.3-15\%) died, no patient recurred, and 12 (2.9\%; 95\% CI: $1.6-4.8 \%)$ experienced major bleeding. The 10-day mortality rate was $9 \%$ (95\% CI: $6-13 \%)$ among patients in hospital wards and 19\% (95\% CI: 13-26\%) among those in ICUs.

The second original study is from Engelen and colleagues, ${ }^{10}$ on VTE in patients discharged after COVID-19 hospitalization. Of interest, the lead writer, Matthias M. Engelen, is a 2021 Eberhard F. Mammen Young Investigator Award winner, ${ }^{11}$ and this manuscript comprises a submission in fulfillment of the award conditions. As already noted, VTE is a frequent complication of COVID-19. Thus, the importance of adequate in-hospital thromboprophylaxis in patients hospitalized with COVID-19 is well established. ${ }^{12,13}$ However, the incidence of VTE after discharge and whether postdischarge thromboprophylaxis is beneficial and safe are unclear. In this prospective observational single-center study, the authors report the incidence of VTE 6 weeks after

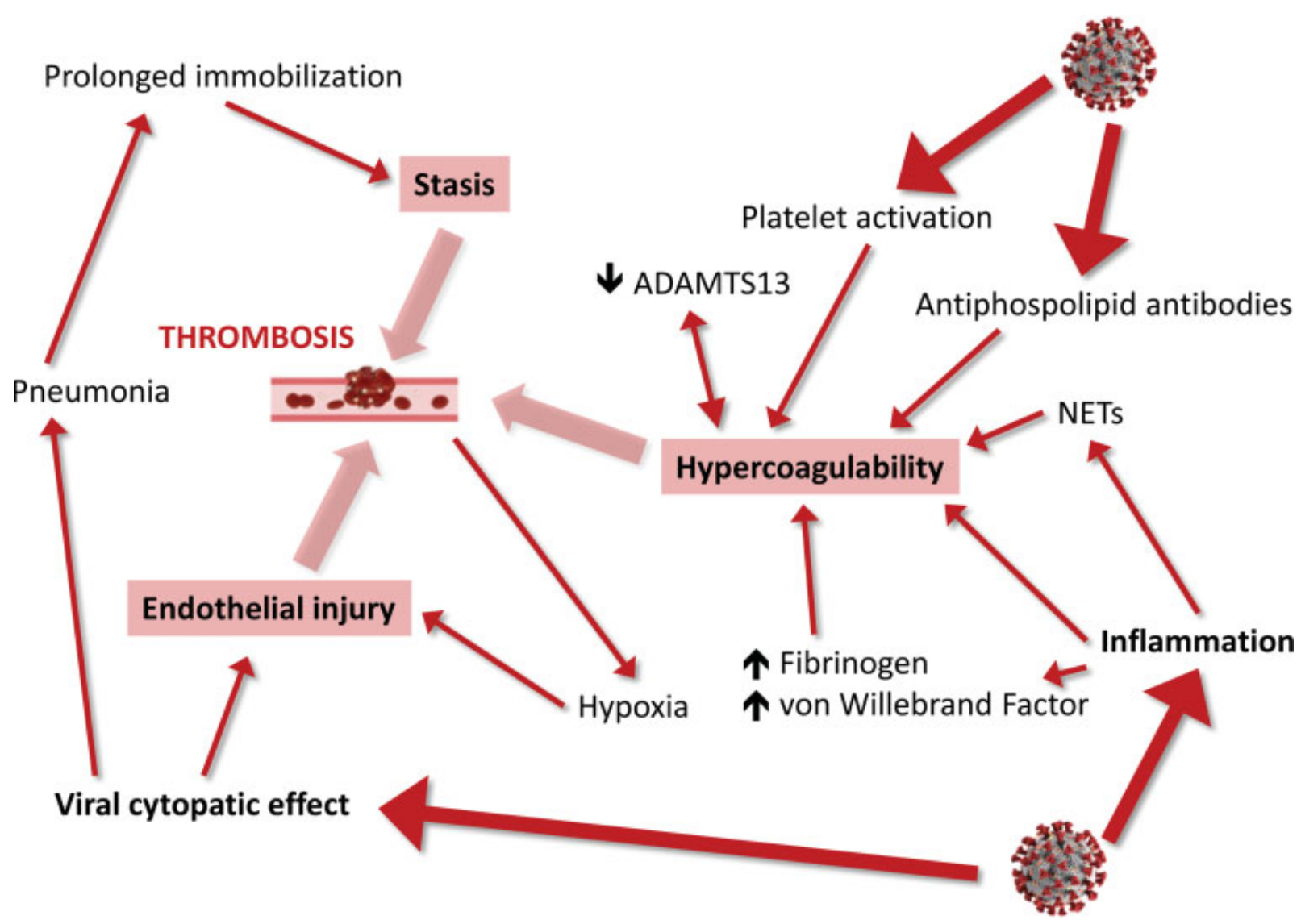

Fig. 1 Pathogenesis of thrombotic complications in severe acute respiratory syndrome coronavirus 2 (SARS-CoV-2) infection. 
hospitalization and the use of postdischarge thromboprophylaxis. Of 485 consecutive patients hospitalized at the time of study completion, data from 146 of these were analyzed, $39 \%$ of whom had been admitted to ICUs. Postdischarge thromboprophylaxis was prescribed in $28 \%$ of patients, but was used more frequently after ICU stay (61\%) as well as in patients with higher maximal D-dimer and C-reactive protein levels during hospitalization. Six weeks after discharge, elevated D-dimer values were present in $32 \%$ of ward and $42 \%$ of ICU patients. Only one asymptomatic DVT $(0.7 \%)$ and one symptomatic PE $(0.7 \%)$ were diagnosed with systematic screening. No bleedings were reported. Thus, in patients who had been hospitalized with COVID-19, systematic screening for VTE 6 weeks after discharge revealed a low incidence of VTE. The authors conclude that a strategy of selectively providing postdischarge thromboprophylaxis in high-risk patients seems safe and potentially effective.

Next in sequence in this issue of STH are several reviews. First, Parisi and coworkers discuss, in a systematic review and an updated meta-analysis, the different anticoagulant regimens, mortality, and bleeding in hospitalized patients with COVID-19. ${ }^{14}$ Articles were retrieved by searching in seven electronic databases. The main outcome was all-cause mortality occurred during hospitalization. Data were combined using the general variance-based method on the effect estimate for each study. Separate meta-analyses according to type of COVID-19 patients (hospitalized or in ICU), anticoagulants (mainly heparin), and regimens (therapeutic or prophylactic) were conducted. From a total of 29 articles selected, 23 retrospective studies were eligible for quantitative meta-analyses. No clinical trial was retrieved. The majority of studies were of good quality; however, 34\% did not distinguish heparin from other anticoagulants. Meta-analysis on 25,719 hospitalized COVID-19 patients showed that anticoagulant use was associated with $50 \%$ reduction in in-hospital mortality risk (pooled risk ratio [RR]:0.50, 95\% CI: 0.40-0.62; $I^{2}: 87 \%$ ). Both anticoagulant regimens (therapeutic and prophylactic) reduced in-hospital all-cause mortality, compared with no anticoagulation. Particularly in ICU patients, anticoagulant therapeutic regimen was associated with a reduced in-hospital mortality risk (RR: $0.30,95 \% \mathrm{CI}: 0.15-0.60 ; I^{2}: 58 \%$ ) compared with the prophylactic one. However, the former was also associated with a higher risk of bleeding (RR: $2.53,95 \% \mathrm{Cl}$ : $1.60-4.00 ; I^{2}: 65 \%$ ). The authors conclude that anticoagulant use, mainly heparin, reduces all-cause mortality in COVID-19 patients during hospitalization. However, due to the higher risk of bleeding at therapeutic doses, the use of prophylactic dosages of anticoagulant is probably to be preferred in noncritically ill COVID-19 patients.

A second meta-analysis is provided by Onorato and colleagues. ${ }^{15}$ As already noted, COVID-19 has affected over 100 million people. ${ }^{3}$ Caused by SARS-CoV-2, COVID-19 expresses as an array of injuries, not limited to the respiratory system, but encompassing also extensive endothelial and systemic tissue damage. Since statins effectively improve endothelial function, these drugs may have beneficial effects in patients COVID-19. Therefore, these authors investigated the interplay between statins and COVID-19, with particular focus on their potentially protective role against progression toward severe or critical illness and death. A systematic electronic search was performed in Scopus and PubMed and data on statin use and COVID-19 outcomes, especially in studies performed in Europe and North America, were extracted and pooled. A total of seven studies met their inclusion criteria, totaling 2,398 patients (1,075 taking statins, i.e., $44.8 \%)$. Overall, statin usage in Western patients hospitalized with COVID-19 was associated with nearly $40 \%$ lower odds of progressing toward severe illness or death (odds ratio: $0.59 ; 95 \% \mathrm{CI}: 0.35-0.99$ ). After excluding studies in which statin therapy was started during hospital admission, the beneficial effect of these drugs was magnified (odds ratio, $0.51 ; 95 \% \mathrm{CI}: 0.41-0.64$ ). Although randomized trials would be necessary to confirm these preliminary findings, the authors conclude that current evidence supports a favorable effect of statins as adjuvant therapy in patients with COVID-19.

Next, the Guest Editors to this issue, along with a third coauthor, present a review on von Willebrand factor (VWF) and ADAMTS13 (a disintegrin and metalloproteinase with a thrombospondin type 1 motif, member 13 ) in COVID-19. ${ }^{16}$ VWF is a large adhesive multimeric protein involved in hemostasis, and the larger the size (or number of VWF multimers), the greater the functionality of the protein. A deficiency or defect of VWF can lead to von Willebrand disease and cause bleeding. ${ }^{17}$ Conversely, an increase in VWF may create an environment that promotes thrombosis. ${ }^{18}$ ADAMTS13, sometimes called VWF-cleaving protease, is primarily responsible for controlling the size of VWF. The severest deficiency of ADAMTS13 $(<10 \%$ of normal levels) arises in thrombotic thrombocytopenic purpura, a condition characterized by the presence of ultra-large VWF and clinically resulting in enhanced risk of thrombosis. ${ }^{19}$ However, ADAMTS13 deficiency may result from other pathological processes. Of relevance is the recent finding that COVID-19 is associated with both increased levels and activity of VWF as well as with generally decreased (or occasionally normal) activity levels of ADAMTS13. Thus, in COVID-19 there is an alteration in the VWF/ADAMTS13 axis, for example as described by increased VWF/ADAMTS13 ratio (or reduced ADAMTS13/VWF ratio, depending on author's preference). As already noted, COVID19 is also associated with high prothrombotic risk. Thus, the imbalance of VWF and ADAMTS13 in COVID-19 may be providing a milieu that promotes (micro)thrombosis (-Fig. 2), in a clinical picture resembling a secondary microangiopathy in some patients. This review therefore assesses the literature on VWF, ADAMTS13, and COVID-19. Whenever reported in COVID-19, VWF has always been identified as raised (compared with normal reference ranges or control populations). Reports have included VWF level and in some cases one or more VWF "activity." Whenever reported, ADAMTS13 has been reported as "normal" or reduced; however, it should be recognized that "normal levels may still identify a relative reduction in individual cases. Of interest, some reports discuss the raised VWF/ADAMTS13 (or reduced ADAMTS13/VWF) ratio, but very few actually provide numerical data. 


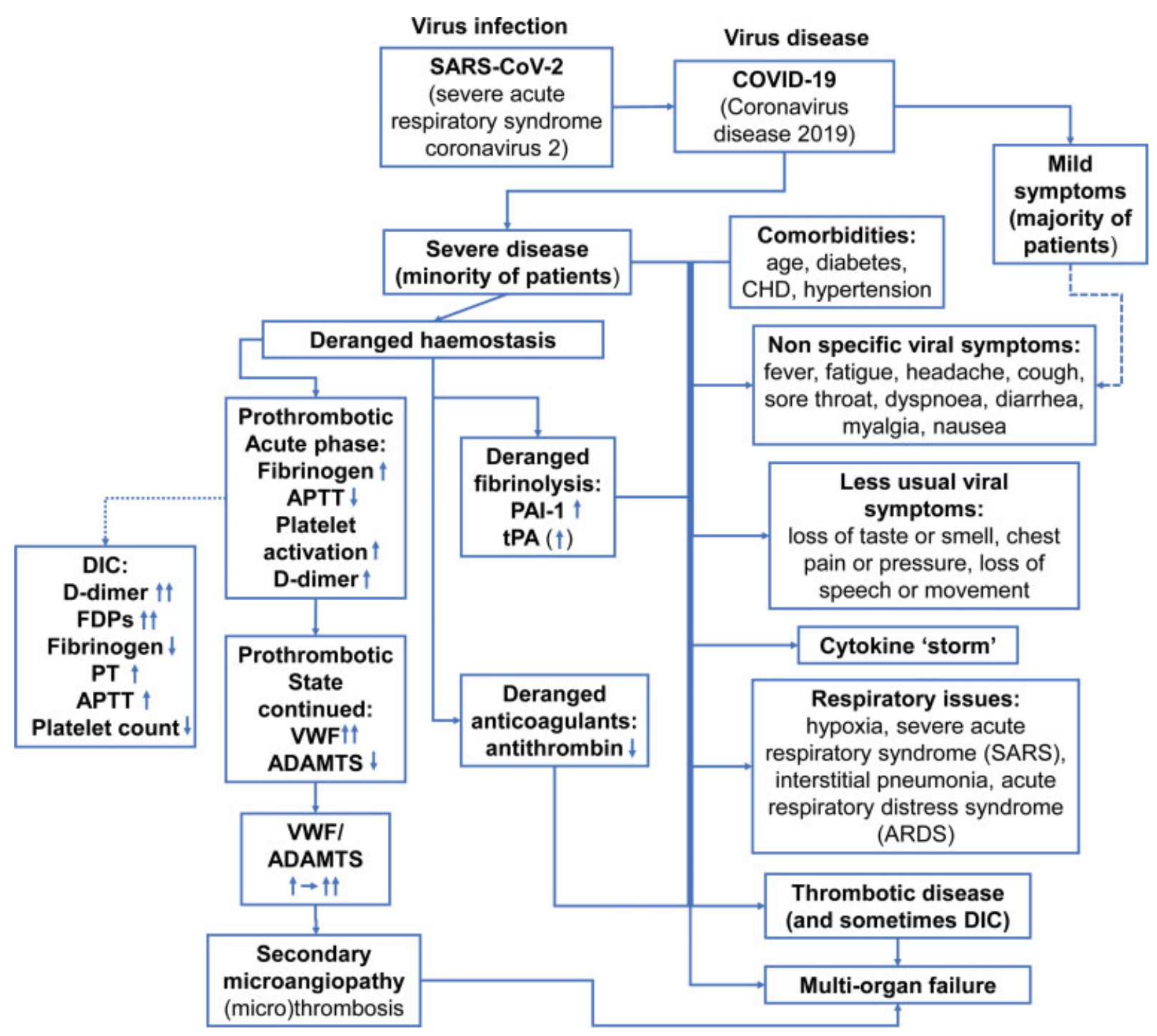

Fig. 2 A summary of coronavirus disease 2019 (COVID-19) issues.

The final review in this issue of STH is by Allaoui and colleagues, ${ }^{20}$ who discuss platelet function in viral immunity and SARS-CoV-2 infection. This is perhaps a fitting extension to the two commentaries on COVID-19 and platelets published in the first issue on COVID-19.21,22 Platelets, as nonnucleated blood components, are classically recognized for their pivotal role in hemostasis. In recent years, however, accumulating evidence points to a nonhemostatic role for platelets, as active participants in the inflammatory and immune responses to microbial organisms in infectious diseases. This stems from the ability of activated platelets to secrete a plethora of immunomodulatory cytokines and chemokines, as well as directly interplaying with viral receptors. While much attention has been given to the role of the so-called cytokine storm in the severity of the COVID-19, less is known about the contribution of platelets to SARS-CoV-2 infection. The authors therefore give an overview on the platelet contribution to antiviral immunity and response during SARS-CoV-2 infection.

The rest of the issue contains several Letters to the Editor. ${ }^{23-31}$ Such "correspondence" permits publication of var- ious "smaller" COVID-19 vignettes. First come two small cases series, the first of which discusses fatal disseminated intravascular coagulopathy (DIC) in COVID- $19,{ }^{23}$ and the second of which discusses pulmonary thrombosis in COVID-19 treated by thrombolysis using streptokinase. ${ }^{24}$ Although initially thought to be common in COVID-19, we now know that DIC is not actually a significant feature of most COVID-19 presentations. ${ }^{32}$ Next comes discussion of efficacy and safety of D-dimer, weight, and renal function-adjusted thromboprophylaxis in a study of 171 patients with COVID- $19,{ }^{25}$ followed by another study of thromboelastography-guided management of anticoagulated COVID-19 patients to prevent hemorrhage. ${ }^{26}$ These are followed in turn by studies looking at (1) thrombin generation in patients with COVID-19, ${ }^{27}$ (2) circulating levels of tissue plasminogen activator and plasminogen activator inhibitor-1 as independent predictors of COVID-19 severity, ${ }^{28}$ (3) mean platelet volume as a predictor of severe COVID-19 illness, ${ }^{29}$ and (4) reduction in plasma antithrombin values in severe COVID-19. ${ }^{30}$ We finish this second issue of STH on COVID-19 with a final thought-provoking question: Does COVID-19 provide a clue for thrombosis in immune thrombocytopenia? ${ }^{31}$ 
We thank all the authors to this second issue of "Maintaining hemostasis and preventing thrombosis in COVID-19" for their original and comprehensive contributions, and we hope the readership of STH enjoys this second installment in this now continuing series. In pages, the issue represents a fairly standard issue length. However, the number of contributions ( $n=17)$ is higher than normal. Like the first issue, ${ }^{1}$ with 23 contributions, the content reflects a wide range of topics and viewpoints on COVID-19 which the readers of STH should appreciate. Finally, we have included in this Preface two figures (-Figs. 1 and 2) that give a kind of overview of COVID-19 from our perspective. The second has been expanded from the figure we included in the first issue Preface. ${ }^{1}$ We ultimately hope that the global vaccination program recently started acts to dampen the pandemic scourge that is COVID-19.

\section{Conflict of Interest \\ None declared.}

\section{References}

1 Favaloro EJ, Lippi G. Maintaining hemostasis and preventing thrombosis in coronavirus disease 2019 (COVID-19)-part I. Semin Thromb Hemost 2020;46(07):757-762

2 Favaloro EJ. Eberhard F. Mammen Award Announcements: Part IMost Popular Articles. Semin Thromb Hemost 2020;46(04):383-392

3 JHU. COVID-19 Dashboard by the Center for Systems Science and Engineering (CSSE) at Johns Hopkins University. . Accessed February 27, 2020 at: https://www.arcgis.com/apps/opsdashboard/ index.html\#/bda7594740fd40299423467b48e9ecf6

4 Harenberg J, Bauersachs R, Ageno W. Does Chronic Treatment with Oral Anticoagulants Ameliorate the Clinical Course of Severe Acute Respiratory Syndrome Coronavirus 2 (SARS-CoV-2) Infection in Coronavirus Disease 2019 (COVID-19)? Semin Thromb Hemost 2021;47(04):338-340

5 Amgalan A, Malinowski AK, Othman M. COVID-19 and sex-/ gender-specific differences: understanding the discrimination. Semin Thromb Hemost 2021;47(04):341-347

6 Nadir Y, Brenner B. Relevance of heparan sulfate and heparanase to severity of COVID-19 in the elderly. Semin Thromb Hemost 2021;47(04):348-350

7 Di Minno A, Ambrosino P, Calcaterra I, Di Minno MND. COVID-19 and venous thromboembolism: a meta-analysis of literature studies. Semin Thromb Hemost 2020;46(07):763-771

8 Nadir Y, Lisman T. Hemostatic and nonhemostatic effects of heparan sulfate proteoglycans. Semin Thromb Hemost 2021;47 (03):238-239

9 Fernández-Capitán C, Barba R, Díaz-Pedroche MDC, et al. Presenting characteristics, treatment patterns, and outcomes among patients with venous thromboembolism during hospitalization for COVID-19. Semin Thromb Hemost 2021;47(04):351-361

10 Engelen MM, Vandenbriele C, Balthazar T, et al. Venous thromboembolism in patients discharged after COVID-19 hospitalization. Semin Thromb Hemost 2021;47(04):362-371

11 Favaloro EJ. 2020 Eberhard F. Mammen Award Announcements: Part II-Young Investigator Awards. Semin Thromb Hemost 2021; 47(03):229-237

12 Bikdeli B, Madhavan MV, Jimenez D, et al;Global COVID-19 Thrombosis Collaborative Group, Endorsed by the ISTH, NATF, ESVM, and the IUA, Supported by the ESC Working Group on Pulmonary Circulation and Right Ventricular Function. COVID-19 and thrombotic or thromboembolic disease: implications for prevention, antithrombotic therapy, and follow-up: JACC stateof-the-art review. J Am Coll Cardiol 2020;75(23):2950-2973
13 Bikdeli B, Madhavan MV, Gupta A, et al;Global CoVID-19 Thrombosis Collaborative Group. Pharmacological agents targeting thromboinflammation in COVID-19: review and implications for future research. Thromb Haemost 2020;120(07):1004-1024

14 Parisi R, Costanzo S, Di Castelnuovo A, de Gaetano G, Donati BM, Iacoviello L. Different anticoagulant regimens, mortality and bleeding in hospitalized patients with COVID-19: a systematic review and an updated meta-analysis. Semin Thromb Hemost 2021;47(04):372-391

15 Onorato D, Pucci M, Carpene G, Henry BM, Sanchis-Gomar F, Lippi G. Protective effects of statins administration in European and North American patients infected with COVID-19: a meta-analysis. Semin Thromb Hemost 2021;47(04):392-399

16 Favaloro EJ, Henry BM, Lippi G. Increased VWF and decreased ADAMTS13 in COVID-19: creating a milieu for (micro)thrombosis? Semin Thromb Hemost 2021;47(04):400-418

17 Zolkova J, Sokol J, Simurda T, et al. Genetic background of von Willebrand disease: history, current state, and future perspectives. Semin Thromb Hemost 2020;46(04):484-500

18 Calabrò P, Gragnano F, Golia E, Grove EL. von Willebrand factor and venous thromboembolism: pathogenic link and therapeutic implications. Semin Thromb Hemost 2018;44(03):249-260

19 Blennerhassett R, Curnow J, Pasalic L. Immune-mediated thrombotic thrombocytopenic purpura: a narrative review of diagnosis and treatment in adults. Semin Thromb Hemost 2020;46(03):289-301

20 Allaoui A, Khawaja AA, Badad O, Naciri M, Lordkipanidzé M, Guessous F, Zaid Y. Platelet function in viral immunity and SARSCoV-2 infection. Semin Thromb Hemost 2021;47(04):419-426

21 Larsen JB, Pasalic L, Hvas A-M. Platelets in coronavirus disease 2019. Semin Thromb Hemost 2020;46(07):823-825

22 Parra-Izquierdo I, Aslan JE. Perspectives on platelet heterogeneity and host immune response in Coronavirus Disease 2019 (COVID19). Semin Thromb Hemost 2020;46(07):826-830

23 Kazmi S, Herekar F, Sarfaraz S. Fatal disseminated intravascular coagulopathy in COVID-19: a small case series. Semin Thromb Hemost 2021;47(04):427-430

24 Caballero López A, Herrera Cartaya C, Chávez González E, et al. Pulmonary thrombosis in COVID-19 treated by thrombolysis: a small case series using streptokinase. Semin Thromb Hemost 2021;47(04):431-435

25 Arachchillage DRJ, Shi C, Saliu D, et al. Efficacy safety and of Ddimer, weight, and renal function-adjusted thromboprophylaxis in patients with coronavirus disease 2019 (COVID-19). Semin Thromb Hemost 2021;47(04):436-441

26 Stillson JE, Bunch CM, Gillespie L, et al. Thromboelastographyguided management of anticoagulated COVID-19 patients to prevent hemorrhage. Semin Thromb Hemost 2021;47(04):442-446

27 Benati M, Salvagno GL, Nitto S, Gelati M, Lavorgna B, Fava C, Minuz P, Lippi G. Thrombin generation in patients with coronavirus disease 2019. Semin Thromb Hemost 2021;47(04):447-450

28 Henry BM, Cheruiyot I, Benoit JL, Lippi G, Prohászka Z, Favaloro EJ, Benoit SW. Circulating levels of tissue plasminogen activator (tPA) and plasminogen activator inhibitor-1 (PAI-1) are independent predictors of coronavirus disease 2019 (COVID-19) severity: a prospective, observational study. Semin Thromb Hemost 2021;47 (04):451-455

29 Lippi G, Henry BM, Favaloro EJ. Mean platelet volume (MPV) predicts severe COVID-19 illness. Semin Thromb Hemost 2021;47 (04):456-459

30 Lippi G, Henry BM, Sanchis-Gomar F. Plasma antithrombin values are significantly decreased in coronavirus disease 2019 (COVID-19) patients with severe illness. Thromb Hemost. 2021;47(04):460-462

31 Thachil J. Does COVID-19 provide a clue for thrombosis in ITP? Semin Thromb Hemost 2021;47(04):463-466

32 Lippi G, Sanchis-Gomar F, Favaloro EJ, Lavie CJ, Henry BM. Coronavirus disease 2019-associated coagulopathy. Mayo Clin Proc 2021;96(01):203-217 